\title{
The effect of melatonin on prevention of bisphosphonate-related osteonecrosis of the jaw: an animal study in rats
}

\author{
Afshin Yadegari ${ }^{1}$, Atousa Aminzadeh ${ }^{2}$, Sam Seyyedkhamesi ${ }^{1, \star}$, Maedeh Aminian ${ }^{3, \dagger}$ \\ ${ }^{1}$ Department of Oral and Maxillofacial Surgery and ${ }^{2}$ Department of Oral Pathology, Faculty of Dentistry, \\ Isfahan (Khorasgan) Branch, Islamic Azad University, ${ }^{3}$ Department of Oral and Maxillofacial Radiology, \\ School of Dentistry, Isfahan University of Medical Science, Isfahan, Iran
}

\begin{abstract}
J Korean Assoc Oral Maxillofac Surg 2020;46:266-274)
Objectives: Melatonin induces human stem cells, converts pre-osteoblasts to mature osteoblasts, and reduces the duration of this transition. However, melatonin itself prevents activation of osteoclasts. Here, we evaluate the role of melatonin in prevention of bisphosphonate-related osteonecrosis of the jaw.

Materials and Methods: In this experimental-interventional study, 30 rats were evaluated in 3 groups. The first and second groups received saline and zoledronic acid, respectively, for 4 weeks and the third group received 4 weeks of zoledronic acid and 3 weeks of melatonin simultaneously. Firstright-maxillary-molar extraction was performed for all animals, which were sacrificed after 4 weeks of recovery. The extraction sockets were examined histologically for the presence of osteonecrosis, number of osteoclasts and fibroblasts, severity of inflammation, and vascularization. Data were analyzed by chi-square, one-way ANOVA, Tukey, Kruskal-Wallis and Fisher's exact statistical tests $(\alpha=0.05)$.

Results: Osteonecrosis was observed in $20 \%, 90 \%$, and $70 \%$ of the first, second and third groups, respectively $(P=0.008)$. The lowest number of osteoclasts and fibroblasts was seen in the third group.

Conclusion: Melatonin may effectively prevent some undesirable side effects of bisphosphonates. However, further studies are required to confirm the results of this study.
\end{abstract}

Key words: Bisphosphonate-related osteonecrosis of the jaw, Diphosphonates, Melatonin

[paper submitted 2019. 7. 6 / revised 2019. 8. 4 / accepted 2019. 8. 17]

\section{Introduction}

Bisphosphonates are synthetic compounds with a chemical structure similar to that of inorganic pyrophosphates. Its

\footnotetext{
Sam Seyyedkhamesi

Department of Oral and Maxillofacial Surgery, Faculty of Dentistry, Isfahan (Khorasgan) Branch, Islamic Azad University, Isfahan, Iran

*Current affiliation: Department of Oral and Maxillofacial Surgery, Faculty of Dentistry, Ardabil University of Medical Science, Daneshgah St., Ardabil 56189-85991, Iran

TEL: +98-9141554717 FAX: +98-45-33534773

E-mail: samadseyyedkhamesi@yahoo.com

ORCID: https://orcid.org/0000-0001-5263-2542

${ }^{\dagger}$ Current affiliation: Department of Oral and Maxillofacial Radiology, Faculty of Dentistry, Ardabil University of Medical Science, Ardabil, Iran
}

(c) This is an open-access article distributed under the terms of the Creative Commons Attribution Non-Commercial License (http://creativecommons.org/ licenses/by-nc/4.0/), which permits unrestricted non-commercial use, distribution, and reproduction in any medium, provided the original work is properly cited.

Copyright (C) 2020 The Korean Association of Oral and Maxillofacial Surgeons. All rights reserved. hydroxyl group binds to hydroxyapatite, and $80 \%$ of the prescribed bisphosphonate precipitates in the bone. Bisphosphonate inhibits bone loss by inducing apoptosis in osteoclasts. It can be used to treat bone-absorbing diseases, such as multiple myeloma and bone metastases from breast and prostate cancers, and hypercalcemia associated with tumors. It is also used to prevent pathological fractures in patients with osteoporosis and to treat Paget's disease, primary and secondary hyperparathyroidism, osteogenesis imperfecta, and other diseases that cause bone fragility ${ }^{1-3}$.

Bisphosphonate-related osteonecrosis of the jaw (BRONJ) is a rare but serious and challenging complication of chronic bisphosphonate consumption. In 2009, the American Association of Oral and Maxillofacial Surgeons (AAOMS) identified BRONJ as a necrotic-bone exposure factor in the jaw that can be probed intra- or extra-orally through a fistula (for more than 8 weeks) in patients who received intravenous (IV) or oral bisphosphonate and who had no history of radiotherapy or metastatic disease in the head and neck ${ }^{4,5}$. 
Most BRONJ cases are related to IV bisphosphonates, and zoledronic acid is the major amino bisphosphonate associated with BRONJ. Most cases are due to dental extraction, dentoalveolar surgery, or trauma from defective dentures, although others have appeared spontaneously ${ }^{6-9}$.

Despite the passing of more than a decade since the introduction of bisphosphonates, the etiopathogenesis of this complication and the standard method for preventing or treating it remain uncertain. The most important factors to consider involve preventing BRONJ oral hygiene and avoiding trauma to the jaw. Any dental work must be completed before beginning treatment with bisphosphonates. Symptoms of dental infection such as jaw/dental pain, swelling and/or redness of the gums after treatment with bisphosphonates, should be reported to the relevant dentist immediately ${ }^{10,11}$.

Various methods, materials, and drugs have been investigated to prevent this complication and some have proven somewhat effective, but none have been approved as a standard method of prevention. Among these methods are the use of triparatide (adjunctive parathyroid hormone) $)^{12-14}$, autologous platelet concentrate ${ }^{15}$, human mesenchymal stem cells ${ }^{3,16}$, antibiotics (penicillin) $)^{17}$, vitamin $\mathrm{D}^{18}$, and geranylgeraniol $^{19}$.(Table 1)
Melatonin is a hormone secreted by numerous organs, including the pineal gland, the retina, bone marrow, digestive tract, and immune system. Its primary function is establishing a daily rhythm (day and night cycle). It also plays anti-inflammatory, anti-cancer, and immunization roles by removing free radicals and reacting with cell membranes and intracellular protein $\mathrm{s}^{20}$. Other effects of melatonin include an increase in osteoblast production, a reduction in their differentiation period, and the prevention of osteoclast activation as a result of bone resorption, anti-fibrotic effects, and angiogenesis effects $^{21-24}$.

The presence of melatonin receptors in healthy oral mucosal cells indicates that melatonin can act as an anti-inflammatory or anticancer agent in the oral cavity ${ }^{25}$. Melatonin has been shown to reduce periodontitis and progression of periodontal bone resorption in diabetic rats ${ }^{20}$ and reduce oxidative stress from tooth removal in $\operatorname{dogs}^{26}$.

The increasing use of bisphosphonates, the incidence of BRONJ, and the lack of a standardized and precise strategy to prevent and reduce its incidence necessitated a study of this issue. Proposed solutions are expensive and access to medications is limited. In this animal study, we evaluated the effect of melatonin, which is available, inexpensive, and as-

Table 1. Summary of effects of factors evaluated in recent studies for prevention or treatment of bisphosphonate-related osteonecrosis of the jaw (BRONJ)

\begin{tabular}{|c|c|c|c|c|}
\hline Factor & Study & Year & Country & Conclusion \\
\hline Estrogen & Vaszilko et al. $^{8}$ & 2014 & Hungary & $\begin{array}{l}\text { Breast cancer patients had a significantly worse prognosis than } \\
\text { patients with other underlying illnesses, which may indicate } \\
\text { antiestrogen therapy was a causative factor. }\end{array}$ \\
\hline \multirow[t]{3}{*}{ Parathyroid hormone } & Keskinruzgar et al. ${ }^{12}$ & 2016 & Turkey & $\begin{array}{l}\text { Teriparatide was found to be effective in eliminating the negative } \\
\text { effects of bisphosphonates on osteoclasts and the inflammatory } \\
\text { phase of bone healing and had positive effects in preventing } \\
\text { osteonecrosis. }\end{array}$ \\
\hline & Dayisoylu et al. ${ }^{13}$ & 2013 & Turkey & $\begin{array}{l}\text { Administration of } 30 \mu \mathrm{g} / \mathrm{kg} / \mathrm{day} \text { parathyroid hormone during } \\
\text { a period of } 8 \text { weeks had positive effects on the resolution of } \\
\text { BRONJ. }\end{array}$ \\
\hline & Zandi et al. ${ }^{14}$ & 2017 & Iran & $\begin{array}{l}\text { Four weeks of triparatide therapy, beginning at the same day or } 2 \\
\text { weeks before tooth extraction, had a potential role in preventing } \\
\text { osteonecrosis of the jaw. }\end{array}$ \\
\hline $\begin{array}{l}\text { Autologous platelet } \\
\text { concentrate (APC) }\end{array}$ & Del Fabbro et al. ${ }^{15}$ & 2015 & Italy & $\begin{array}{l}\text { A review of results of } 18 \text { studies is suggestive of possible benefits } \\
\text { of APC when associated with surgical procedures for treatment or } \\
\text { prevention of BRONJ. }\end{array}$ \\
\hline \multirow[t]{2}{*}{ Mesenchymal stem cell (MSC) } & Kaibuchi et al. $^{3}$ & 2016 & Japan & $\begin{array}{l}\text { Allogeneic MSC sheet transplantation is a promising alternative } \\
\text { approach for treating BRONJ. }\end{array}$ \\
\hline & Ogata et al. ${ }^{16}$ & 2015 & Japan & $\begin{array}{l}\text { The anti-apoptotic and anti-inflammatory effects of MSC drama- } \\
\text { tically regulated the turnover of local bone and indicated the- } \\
\text { rapeutic effects on BRONJ. }\end{array}$ \\
\hline Antibiotic (penicillin) & López-Jornet et al. ${ }^{17}$ & 2011 & Spain & $\begin{array}{l}\text { Antibiotic prophylaxis in invasive dental procedures results in a } \\
\text { significant decrease in BRONJ. }\end{array}$ \\
\hline Vitamin D & Yanık et al. ${ }^{18}$ & 2016 & Turkey & $\begin{array}{l}\text { There is some evidence for the treatment of BRONJ with systemic } \\
\text { use of vitamin D. }\end{array}$ \\
\hline Geranylgeraniol & Koneski et al. ${ }^{19}$ & 2018 & Macedonia & $\begin{array}{l}\text { Geranylgeraniol in a local solution form may be a promising option } \\
\text { for prevention and treatment of BRONJ. }\end{array}$ \\
\hline
\end{tabular}

Afshin Yadegari et al: The effect of melatonin on prevention of bisphosphonate-related osteonecrosis of the jaw: an animal study in rats. J Korean Assoc Oral Maxillofac Surg 2020 
sociated with few side effects, on the onset of BRONJ.

\section{Materials and Methods}

\section{Animals}

In this experimental-interventional study, 30 male Wistar albino rats (12 weeks old, weighted 250-300 g each, without infections or pathologic conditions) were selected by a simple sampling method. Experiments were carried out in accordance with guidelines from the European Community Council Directive of 24 November 1986 (86/609/ EEC) and the Ethics Committee of Islamic Azad University, Khorasgan Branch approved the study (IR.IAU.KHUISF. REC.1397.262). All rats were fed a standard rodent diet and kept in a monitored environment at $22^{\circ} \mathrm{C} \pm 2{ }^{\circ} \mathrm{C}, 40 \%$ to $60 \%$ humidity, and a 12/12-h light/dark cycle.

\section{Experimental design and surgical procedure}

The rats were randomly assigned into 3 groups (10 samples per group). Rats in group 1 received an intraperitoneal (IP) injection of $0.1 \mathrm{mg} / \mathrm{kg}$ saline 3 times a week for 4 weeks. Rats in group 2 received an IP injection of $0.1 \mathrm{mg} / \mathrm{kg}$ zoledronic acid (Zolena; Ronak Pharmaceutical, Saveh, Iran) 3 times a week for 4 weeks. Rats in group 3 received an injection of zoledronic acid $(0.1 \mathrm{mg} / \mathrm{kg})$ similar to the injection for group 2. In addition, $5 \mathrm{mg} / \mathrm{kg} / \mathrm{day}$ of melatonin (Melatonin, Nature Made, CA, USA) was given orally for 3 weeks with a laboratory pipette attached to an insulin syringe $(100 \mathrm{mg} /$ $\mathrm{kg}$ total dose) between 4 p.m. and 5 p.m., when the concentration of melatonin in the blood was minimal, so that the courses of the two drugs were completed at the same time.

At the end of the 4-week period, the first-right-maxillary molar tooth of each rats was extracted under IP general anesthesia using $70 \mathrm{mg} / \mathrm{kg}$ of ketamine (ketamine 10\%; Alfasan, Woerden, Netherlands) and $12 \mathrm{mg} / \mathrm{kg}$ xylazine (xylazin $2 \%$; Alfasan). The rats of the 3 groups were sacrificed after 4 weeks of recovery.

\section{Histopathological analysis}

A $5 \mu \mathrm{m}$ thick axial section in the mid-root region was cut from each tooth socket. For each sample, routine laboratory processing procedures were performed and staining with H\&E was carried out.

Tissue analysis was performed by a pathologist blinded to the treatment groups using a light microscope (Nikon, Tokyo, Japan) in 5 consequent histopathologic fields (HPFs) (with $40 \times$ or $10 \times$ magnification) without overlapping. Several histological parameters were examined:

1) Osteonecrosis foci: Defined as 8 to 10 adjacent empty lacunae (without osteocytes) in the alveolar bone. The number of these foci was also counted in 5 non-overlapping HPFs with $10 \times$ magnification ${ }^{27}$.(Fig. 1)

2) Number of osteoclasts: The number of osteoclasts from the alveolar bone surface around the sockets was counted ${ }^{27}$. (Fig. 2. A)

3) Number of fibroblasts: The number of fibroblasts inside the sockets near the alveolar bone surface (Fig. 2. B) was counted and each was graded as Grade 0 (fewer than 30 cells), Grade 1 ( $31-50$ cells), Grade 2 (51-75 cells), or Grade 3 (more than 76 cells) ${ }^{13}$.

4) Inflammation intensity: Inflammation severity was measured by counting the number of lympho-plasmocytes from the alveolar bone surface around the sockets (Fig. 2. C) and graded as Grade 0 (no inflammation), Grade I (fewer than 10 lymphoplasmocytes), Grade II (11-25 lymphoplasmocytes), Grade III (26-50 lymphoplasmocytes), or Grade IV (more than 50 lymphoplasmocytes) $)^{17,18}$.

5) Vascularization: Vascularization was evaluated by counting the number of capillaries from the alveolar bone surface of the sockets (Fig. 2. D) and graded as Grade 1 (fewer than 10 capillaries) or Grade 2 (more than 10 capillaries) ${ }^{17}$.

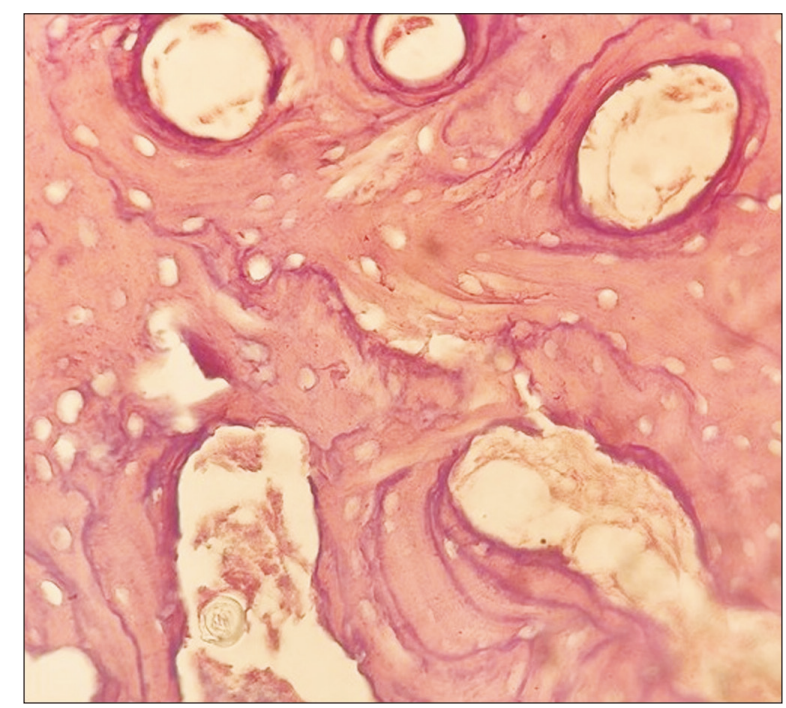

Fig. 1. Foci of osteonecrosis. Osteocyte-free lacunas are visible (light microscope, $\times 10$; H\&E staining).

Afshin Yadegari et al: The effect of melatonin on prevention of bisphosphonate-related osteonecrosis of the jaw: an animal study in rats. J Korean Assoc Oral Maxillofac Surg 2020 

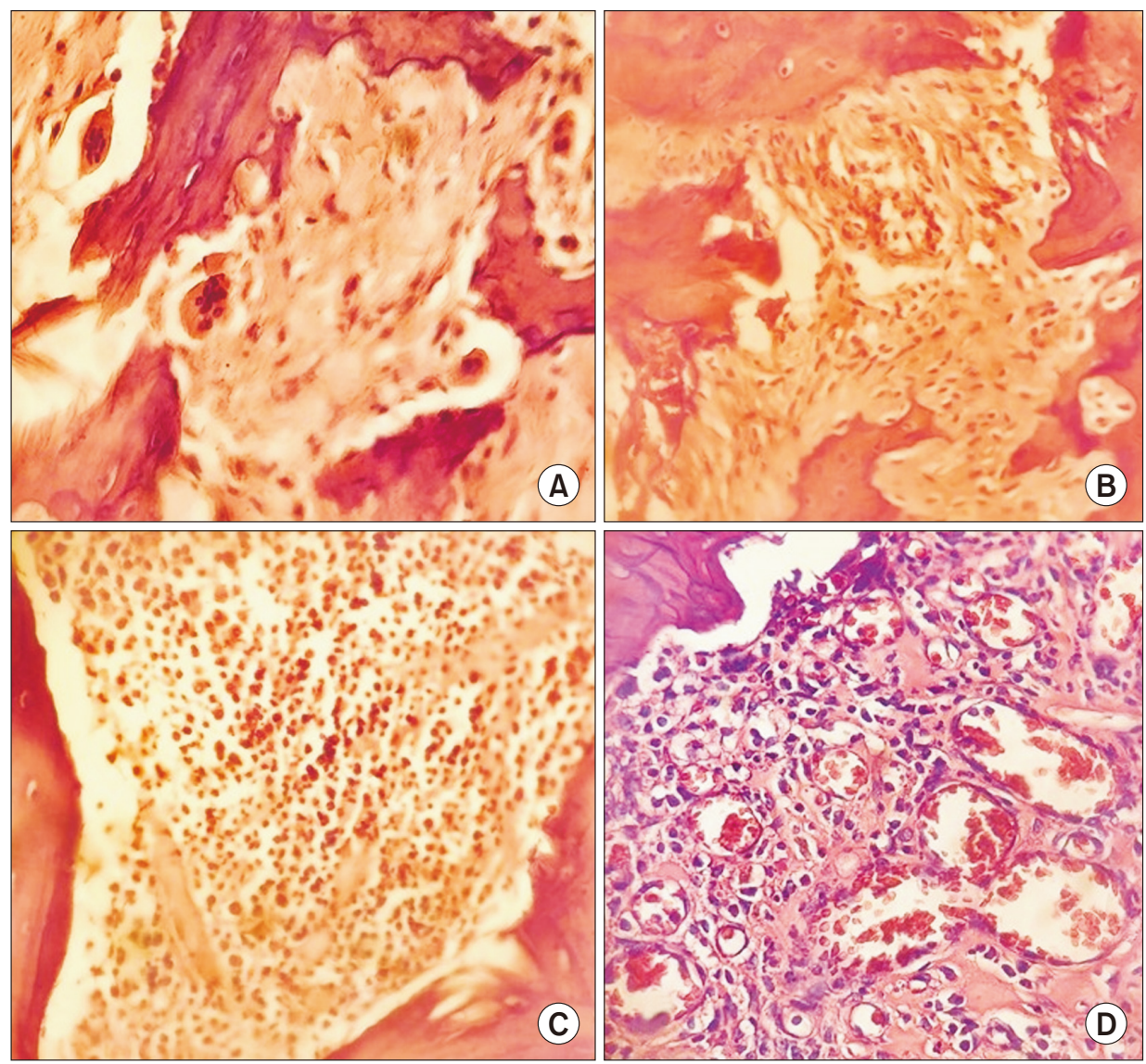

Fig. 2. Histopathologic fields (light microscope, $\times 40$; H\&E staining). A. Giant cell osteoclasts next to bone. B. Foci of fibroblasts. C. Foci of inflammation. D. Capillaries with engorging red blood cells.

Afshin Yadegari et al: The effect of melatonin on prevention of bisphosphonate-related osteonecrosis of the jaw: an animal study in rats. J Korean Assoc Oral Maxillofac Surg 2020

Table 2. Comparison of presence of osteonecrosis, number of osteonecrosis foci and osteoclasts between the 3 groups of rats

\begin{tabular}{lcccc}
\hline \multicolumn{1}{c}{ Variable } & Group 1 $(\mathrm{n}=10)$ & Group 2 $(\mathrm{n}=10)$ & Group 3 $(\mathrm{n}=10)$ & $P$-value \\
\hline Presence of osteonecrosis & $2(20.0)$ & $9(90.0)$ & $7(70.0)$ & $0.008^{*}$ \\
No. of osteonecrosis foci & $0.4 \pm 0.84$ & $3.6 \pm 1.57$ & $2.2 \pm 1.68$ & $0.0001^{*}$ \\
No. of osteoclasts & $4.5 \pm 3.56$ & $0.2 \pm 0.42$ & $0.5 \pm 0.84$ & $0.0001^{*}$ \\
\hline
\end{tabular}

(Group 1: control [saline], Group 2: zolendronic acid, Group 3: zolendronic acid+melatonin)

$* P<0.05$, statistically significant difference between the 3 groups.

Values are presented as number (\%) or mean \pm standard deviation.

Afshin Yadegari et al: The effect of melatonin on prevention of bisphosphonate-related osteonecrosis of the jaw: an animal study in rats. J Korean Assoc Oral Maxillofac Surg 2020

\section{Data analysis}

Data were inserted in and analyzed with IBM SPSS Statistics (ver. 22; IBM, Armonk, NY, USA). To compare the quantitative variables between the 3 groups, we used oneway ANOVA for variables with a normal distribution and Kruskal-Wallis tests for those without normal distribution. Tukey's post hoc test was used for pairwise comparison where one-way ANOVA showed significant results. A chisquare test and Fisher's exact test were used to compare frequency distributions of the qualitative variables among the 3 groups of the study. A $P<0.05$ was considered statistically significant.

\section{Results}

The comparison of presence of osteonecrosis, the number of osteonecrosis foci, and osteoclasts among the 3 groups is demonstrated in Table 2. Osteonecrosis was observed in $20 \%$, $90 \%$, and $70 \%$ of the first, second, and third group, respectively, and a chi-square test showed a significant relationship among the 3 groups $(P=0.008)$. One-way ANOVA revealed a significant difference in the average number of osteonecrosis foci between the three groups $(P=0.0001)$. Tukey's post hoc test revealed that the number of osteonecrosis foci in rats of the first group was significantly lower than those in the rats of both the second $(P=0.0001)$ and third group $(P=0.023)$. However, the difference in the number of osteonecrosis 
Table 3. Comparison of the grade of fibroblasts between the 3 groups of rats

\begin{tabular}{|c|c|c|c|c|}
\hline Variable & Group $1(n=10)$ & Group $2(n=10)$ & Group $3(n=10)$ & $P$-value \\
\hline Grade of fibroblasts & & & & $0.006^{*}$ \\
\hline Grade 0 & $0(0)$ & $2(20.0)$ & $6(60.0)$ & \\
\hline Grade 1 & $7(70.0)$ & $4(40.0)$ & $4(40.0)$ & \\
\hline Grade 2 & $1(10.0)$ & $4(40.0)$ & $0(0)$ & \\
\hline Grade 3 & $2(20.0)$ & $0(0)$ & $0(0)$ & \\
\hline
\end{tabular}

(Group 1: control [saline], Group 2: zolendronic acid, Group 3: zolendronic acid+melatonin, Grade 0: fewer than 30 cells, Grade 1: $31-50$ cells, Grade 2: 51-75 cells, Grade 3: more than 76 cells)

$* P<0.05$, statistically significant difference between 3 groups.

Values are presented as number $(\%)$.

Afshin Yadegari et al: The effect of melatonin on prevention of bisphosphonate-related osteonecrosis of the jaw: an animal study in rats. J Korean Assoc Oral Maxillofac Surg 2020

Table 4. Comparison of inflammation severity between the 3 groups of rats

\begin{tabular}{cccc}
\hline Variable & Group 1 $(\mathrm{n}=10)$ & Group 2 $(\mathrm{n}=10)$ & Group 3 $(\mathrm{n}=10)$ \\
\hline Grade of inflammation & & & \\
Grade 0 & $3(30.0)$ & $5(50.0)$ & $5(50.0)$ \\
Grade I & $1(10.0)$ & $2(20.0)$ & $4(40.0)$ \\
Grade II & $3(30.0)$ & $3(30.0)$ & $1(10.0)$ \\
Grade III & $2(20.0)$ & $0(0)$ & $0(0)$ \\
Grade IV & $1(10.0)$ & $0(0)$ & $0(0)$ \\
\hline
\end{tabular}

(Group 1: control [saline], Group 2: zolendronic acid, Group 3: zolendronic acid+melatonin, Grade 0: no inflammation, Grade I: fewer than 10 lymphoplasmocytes, Grade II: 11-25 lymphoplasmocytes, Grade III: 26-50 lymphoplasmocytes, Grade IV: more than 50 lymphoplasmocytes) Values are presented as number $(\%)$.

Afshin Yadegari et al: The effect of melatonin on prevention of bisphosphonate-related osteonecrosis of the jaw: an animal study in rats. J Korean Assoc Oral Maxillofac Surg 2020

Table 5. Comparison of vascularization rate between 3 groups of rats

\begin{tabular}{|c|c|c|c|c|}
\hline Variable & Group $1(n=10)$ & Group $2(n=10)$ & Group $3(n=10)$ & $P$-value \\
\hline Grade of vascularization & & & & 0.5 \\
\hline Grade 1 & $5(50.0)$ & $8(80.0)$ & $7(70.0)$ & \\
\hline Grade 2 & $5(50.0)$ & $2(20.0)$ & $3(30.0)$ & \\
\hline
\end{tabular}

(Group 1: control [saline], Group 2: zolendronic acid, Group 3: zolendronic acid+melatonin, Grade 1: fewer than 10 capillaries, Grade 2: more than 10 capillaries)

Values are presented as number $(\%)$.

Afshin Yadegari et al: The effect of melatonin on prevention of bisphosphonate-related osteonecrosis of the jaw: an animal study in rats. J Korean Assoc Oral Maxillofac Surg 2020

foci between the second and third group was not significant $(P=0.088)$. The mean numbers of osteoclasts were $5.5,0.2$, and 0.5 in the first, second, and third group, respectively, and a Kruskal-Wallis test showed a statistically significant difference among the 3 groups $(P=0.0001)$.

A comparison of the degree of fibroblasts in the 3 groups is shown in Table 3 . None of the first group, $20 \%$ of the second group, and $60 \%$ of the third group showed fibroblast production inside the dental socket. There were no Grade 3 fibroblasts in the second group or Grade 2 or 3 fibroblasts in the third group, and Fisher's exact tests demonstrated a significant difference between the number of fibroblasts in the 3 groups $(P=0.006)$.

Table 4 supplies the frequency distribution of inflammation severity in the 3 groups. Thirty percent of the first group and half of the second and third group had no inflammation. Grade 4 inflammation was seen in $10 \%$ of the first group, while there were no cases of Grade 3 and 4 inflammation in second and third groups of rats. Fisher's exact tests showed no statistically significant differences among the 3 groups $(P=0.39)$.

A comparison of the vascularization rate was performed in the 3 groups using Fisher's exact test.(Table 5) Half of the first group, $80 \%$ of the second group, and $70 \%$ of the third group had Grade 1 vascularization (fewer than 10 capillaries), but no significant correlation was found among the 3 groups $(P=0.5)$.

\section{Discussion}

A rat model was used to evaluate the effect of melatonin on the occurrence and development of BRONJ. Rats were chosen due to their low cost, rapid and easy reproduction, and the availability of simple maintenance conditions compared 
with other model species.

Zoledronic acid is the most potent and most used IV bisphosphonate and is associated with the highest risk of developing BRONJ ${ }^{28}$. In the present study, following the example of most of the previous studies, we used this type of bisphosphonate.

We also compared histopathologic factors, including the presence and number of osteonecrosis foci, number of osteoclasts, number of fibroblasts, inflammation severity, and vascularization rates among the three groups, instead of the BRONJ classification system identified by AAOMS ${ }^{2}$. This was due to our inability to measure subjective symptoms in the rat, and some differences in the anatomy of the rat relative to humans.

\section{Presence and number of osteonecrosis foci}

In this study, the presence of osteonecrosis was defined as 8 to 10 adjacent empty lacunae without osteocytes. In Zandi et al. ${ }^{28}$, in which a protocol for creating BRONJ in rat models was introduced, 8 contiguous empty lacunae were considered indicative of osteonecrosis.

In the present study, the highest rate of osteonecrosis was seen in rats of the second group (90\%), followed by the third (70\%) and first $(20 \%)$ groups $(P=0.008)$. The average number of osteonecrosis foci in the first group was significantly lower than that of the other two groups. The amount was also lower in the third group than in the second group, but the difference was not statistically significant $(P=0.088)$. The greater amount of osteonecrosis in the second group compared with the first group was predictable, well-documented, and similar to all previous studies ${ }^{13,15-18,27,29-31}$. The difference in the rate of osteonecrosis and BRONJ in bisphosphonatetreated groups reported in various studies was likely due to the dose, route of administration (oral, IV injection, IP injection), type of bisphosphonate, and duration of drug consumption. In addition, some studies used a corticosteroid drug such as dexamethasone with bisphosphonate to increase the risk of osteonecrosis and BRONJ ${ }^{17,18}$. The lower incidence of osteonecrosis in the rats that received melatonin suggesting the probability of effectiveness of this inexpensive and available drug to prevent the onset of BRONJ in patients who consume bisphosphonate. So far, no study has examined osteonecrosis after administration of melatonin. However, previous studies indicate that melatonin has antioxidant properties and is a free-radical scavenger ${ }^{20-22,32-34}$, and according to a study by Cutando et al. ${ }^{26}$, topical application of melatonin to dental extraction sockets eliminated both oxidative stress and its effects and accelerated dental socket healing. On the other hand, melatonin increases and accelerates differentiation of precursor cells into osteoblasts ${ }^{21}$. These properties can partly explain the reduction in the occurrence of osteonecrosis in the dental sockets of rats that received melatonin.

\section{Number of osteoclasts}

The highest number of osteoclasts was seen in the first group (5.5), followed by the third (0.5) and second (0.2) groups, respectively. The differences were statistically significant $(P=0.0001)$. The severe reduction in the number of osteoclasts in the second group compared with the first group - similar to the osteonecrosis - was reasonable, well-documented, and in agreement with previous studies $^{13,15-18,27,29-31}$. The reduction can be attributed to the mechanism of bisphosphonate (as previously mentioned), which causes apoptosis of osteoclasts. In the present study, the number of osteoclasts in the third group was higher than that of the second group. According to previous studies, melatonin inhibits activation of osteoclasts by preventing binding between the receptor activator of nuclear factor- $\kappa \mathrm{B}$ ligand of osteoblasts to the receptor activator of nuclear factor- $\kappa \mathrm{B}$ of osteoclasts ${ }^{35}$. However, it does not induce apoptosis in the osteoclasts. According to a study by Dayisoylu et al. ${ }^{13}$, the release of bisphosphonates from the hydroxyapatite of the bone at the site of tooth extraction, which causes apoptosis of target cells including osteoclasts, requires inflammation and inflammatory mediators. Melatonin has anti-inflammatory, anti-free radical, and anti-oxidative stress effects $22,26,33,34$ and can be effective in preventing the induction of apoptosis in osteoclasts by bisphosphonates.

\section{Number of fibroblasts}

To determine the rate of regeneration, we compared the number of fibroblasts by counting them inside the sockets near the alveolar bone surface and grading them from 0 to 3 . In the first group, there was no Grade 0 fibroblasts, while $20 \%$ of the second group and $60 \%$ of the third group showed no fibroblast production inside the dental socket. The lowest number of fibroblasts was seen in the third group. By contrast, Dayisoylu et al. ${ }^{13}$, who studied zoledronic acid in a tooth-extraction group, found that the number of fibroblasts was higher than both the first group and the zoledronic acid without tooth-extraction group. No conclusions or discus- 
sion regarding this result or its probable explanations were included in that study. In a study by Gómez-Florit et al. ${ }^{22}$, which evaluated the anti-fibrotic effect of melatonin on human gingival fibroblasts, higher concentrations of melatonin reportedly had cytotoxic effects on fibroblasts and caused them to die, but lower concentrations were associated with increased collagen production. The authors found that $1 \mathrm{~mol}$ of melatonin was safe for fibroblasts, and that melatonin improved wound healing without scarring. The amounts and route of administration of melatonin in the present study appear to be higher than safe levels for fibroblasts, resulting in a severe reduction in their levels in dental sockets of the third group compared with the first group.

\section{Inflammation severity}

The severity of inflammation was calculated by counting the number of lympho-plasmocytes from the alveolar bone surrounding the dental sockets and dividing them into 5 grades from 0 to 4 . In the first group, $30 \%$ had no inflammation and $10 \%$ had Grade 4 inflammation, while half of the rats of the second group and third group had Grade 0 inflammation. No Grade 3 and 4 inflammation was observed in the rats in the second and third groups. Level 1 inflammation in the melatonin group (40\%) was twice that of the second group $(20 \%)$. However, no significant relationship was found between the differences $(P=0.39)$. Most studies have reported an anti-angiogenesis and anti-immune effect for bisphosphonate $^{12,28}$ and an anti-inflammatory effect for melatonin ${ }^{20-22,32-34}$. The lack of a statistically significant difference in our study may be due to the insufficient sample size or the large number of severe-grade inflammation.

\section{Vascularization}

The rate of vascularization was measured by counting the number of capillaries on the alveolar bone surface in the dental socket and classifying by grade. In ascending order, 50\% of the first group, $70 \%$ of the third group, and $80 \%$ of the second group had Grade 1 vascularization (fewer than 10 capillaries), but no significant correlation was found between the 3 groups $(P=0.5)$. Previous studies found an anti-angiogenesis mechanism for bisphosphonates ${ }^{17,19}$ and a positive effect of melatonin on angiogenesis and wound healing ${ }^{23,24}$. The lack of a statistically significant difference in our study may be due to the insufficient sample size or the lack of Grade 0 in the classification system that we used to separate the sockets with a lack of vascularization from those with reduced vascularization.

\section{Conclusion}

Melatonin may be effective in preventing some undesirable side effects of bisphosphonates, such as osteonecrosis and decreasing osteoclasts in the dental socket area. However, its anti-fibrotic effect is not desirable. Our study was the first in this field and more studies are required to confirm its results. We encountered some limitations, such as difficulty conducting clinical examination of rat bones, as well as high costs and difficulty preparing zoledronic acid. Similar studies should be designed with larger sample sizes, different doses and routes of administration, and duration of melatonin, with particular emphasis on local placement in dental sockets, use of BRONJ clinical criteria, immuno-histo-chemical staining, radiographic and micro-computed tomography, and in vivo conditions.

\section{ORCID}

\begin{abstract}
Afshin Yadegari, https://orcid.org/0000-0002-4474-6096
Atousa Aminzadeh, https://orcid.org/0000-0001-5489-7499

Sam Seyyedkhamesi, https://orcid.org/0000-0001-5263-2542

Maedeh Aminian, https://orcid.org/0000-0003-1087-5209
\end{abstract}

\section{Authors' Contributions}

S.S. and M.A. participated in data collection and coordination and wrote the manuscript. A.A., S.S., and M.A. participated in the study design. A.Y. is the supervision of the study and he read and approved the final manuscript. All authors read and approved the final manuscript.

\section{Acknowledgements}

We thank Mr. Hafezi for data analysis.

\section{Ethics Approval and Consent to Participate}

Experiments were carried out in accordance with guidelines from the European Community Council Directive of 24 November 1986 (86/609/EEC) and the Ethics Committee of Islamic Azad University, Khorasgan Branch approved the study (IR.IAU.KHUISF.REC.1397.262). 


\section{Conflict of Interest}

No potential conflict of interest relevant to this article was reported.

\section{References}

1. Ruggiero SL, Dodson TB, Fantasia J, Goodday R, Aghaloo T, Mehrotra B, et al.; American Association of Oral and Maxillofacial Surgeons. American Association of Oral and Maxillofacial Surgeons position paper on medication-related osteonecrosis of the jaw--2014 update. J Oral Maxillofac Surg 2014;72:1938-56. https://doi.org/10.1016/j.joms.2014.04.031

2. Ikebe T. Pathophysiology of BRONJ: drug-related osteoclastic disease of the jaw. Oral Sci Int 2013;10:1-8. https://doi.org/10.1016/ S1348-8643(12)00045-6

3. Kaibuchi N, Iwata T, Yamato M, Okano T, Ando T. Multipotent mesenchymal stromal cell sheet therapy for bisphosphonaterelated osteonecrosis of the jaw in a rat model. Acta Biomater 2016;42:400-10. https://doi.org/10.1016/j.actbio.2016.06.022

4. Colella G, Campisi G, Fusco V. American Association of Oral and Maxillofacial Surgeons position paper: bisphosphonate-related osteonecrosis of the jaws-2009 update: the need to refine the BRONJ definition. J Oral Maxillofac Surg 2009;67:2698-9. https://doi. org/10.1016/j.joms.2009.07.097

5. Kos M, Kuebler JF, Luczak K, Engelke W. Bisphosphonaterelated osteonecrosis of the jaws: a review of 34 cases and evaluation of risk. J Craniomaxillofac Surg 2010;38:255-9. https://doi. org/10.1016/j.jcms.2009.06.005

6. Otto S, Schreyer C, Hafner S, Mast G, Ehrenfeld M, Stürzenbaum $\mathrm{S}$, et al. Bisphosphonate-related osteonecrosis of the jaws - characteristics, risk factors, clinical features, localization and impact on oncological treatment. J Craniomaxillofac Surg 2012;40:303-9. https://doi.org/10.1016/j.jcms.2011.05.003

7. Pichardo SE, van Merkesteyn JP. Bisphosphonate related osteonecrosis of the jaws: spontaneous or dental origin? Oral Surg Oral Med Oral Pathol Oral Radiol 2013;116:287-92. https://doi. org/10.1016/j.oooo.2013.05.005

8. Vaszilko M, Kovacs E, Restar L, Balla B, Cseplo K, Kosa J, et al. Potential significance of antiestrogen therapy in the development of bisphosphonate related osteonecrosis of the jaw. J Craniomaxillofac Surg 2014;42:1932-6. https://doi.org/10.1016/j.jcms.2014.08.002

9. Voss PJ, Joshi Oshero J, Kovalova-Müller A, Veigel Merino EA, Sauerbier S, Al-Jamali J, et al. Surgical treatment of bisphosphonate-associated osteonecrosis of the jaw: technical report and follow up of 21 patients. J Craniomaxillofac Surg 2012;40:719-25. https://doi.org/10.1016/j.jcms.2012.01.005

10. Udell J. Osteonecrosis [Internet]. Atlanta (GA): American College of Rheumatology [cited 2019 Feb 9]. Available from: https://www. rheumatology.org/I-Am-A/Patient-Caregiver/Diseases-Conditions/ Osteonecrosis.

11. Udell J. Osteonecrosis of the jaw [Internet]. Atlanta (GA): American College of Rheumatology [cited 2019 Feb 9]. Available from: https://www.rheumatology.org/I-Am-A/Patient-Caregiver/Diseases-Conditions/Osteonecrosis.

12. Keskinruzgar A, Bozdag Z, Aras MH, Demir T, Yolcu U, Cetiner S. Histopathological effects of teriparatide in medication-related osteonecrosis of the jaw: an animal study. J Oral Maxillofac Surg 2016;74:68-78. https://doi.org/10.1016/j.joms.2015.07.005

13. Dayisoylu EH, Şenel FÇ, Üngör C, Tosun E, Çankaya M, Ersöz $\mathrm{S}$, et al. The effects of adjunctive parathyroid hormone injection on bisphosphonate-related osteonecrosis of the jaws: an animal study. Int J Oral Maxillofac Surg 2013;42:1475-80. https://doi. org/10.1016/j.ijom.2013.05.001
14. Zandi M, Dehghan A, Mohammadi-Mofrad A, Amini P, Vahdatinia F. Short-term perioperative teriparatide therapy for the prevention of medication-related osteonecrosis of the jaw: a randomized, controlled preclinical study in rats. J Craniomaxillofac Surg 2017;45:275-80. https://doi.org/10.1016/j.jcms.2016.12.010

15. Del Fabbro M, Gallesio G, Mozzati M. Autologous platelet concentrates for bisphosphonate-related osteonecrosis of the jaw treatment and prevention. A systematic review of the literature. Eur J Cancer 2015;51:62-74. https://doi.org/10.1016/j.ejca.2014.10.015

16. Ogata K, Katagiri W, Osugi M, Kawai T, Sugimura Y, Hibi H, et al. Evaluation of the therapeutic effects of conditioned media from mesenchymal stem cells in a rat bisphosphonate-related osteonecrosis of the jaw-like model. Bone 2015;74:95-105. https://doi. org/10.1016/j.bone.2015.01.011

17. López-Jornet P, Camacho-Alonso F, Martínez-Canovas A, MolinaMiñano F, Gómez-García F, Vicente-Ortega V. Perioperative antibiotic regimen in rats treated with pamidronate plus dexamethasone and subjected to dental extraction: a study of the changes in the jaws. J Oral Maxillofac Surg 2011;69:2488-93. https://doi. org/10.1016/j.joms.2011.02.059

18. Yanık S, Aras MH, Erkılıç S, Bozdağ Z, Demir T, Çetiner S. Histopathological features of bisphosphonates related osteonecrosis of the jaw in rats with and without vitamin d supplementation. Arch Oral Biol 2016;65:59-65. https://doi.org/10.1016/ j.archoralbio.2015.10.010

19. Koneski F, Popovic-Monevska D, Gjorgoski I, Krajoska J, Popovska M, Muratovska I, et al. In vivo effects of geranylgeraniol on the development of bisphosphonate-related osteonecrosis of the jaws. J Craniomaxillofac Surg 2018;46:230-6. https://doi.org/10.1016/ j.jcms.2017.11.007

20. Najeeb S, Khurshid Z, Zohaib S, Zafar MS. Therapeutic potential of melatonin in oral medicine and periodontology. Kaohsiung J Med Sci 2016;32:391-6. https://doi.org/10.1016/ j.kjms.2016.06.005

21. Carpentieri AR, Peralta Lopez ME, Aguilar J, Solá VM. Melatonin and periodontal tissues: molecular and clinical perspectives. Pharmacol Res 2017;125(Pt B):224-31. https://doi.org/10.1016/ j.phrs.2017.09.003

22. Gómez-Florit M, Ramis JM, Monjo M. Anti-fibrotic and antiinflammatory properties of melatonin on human gingival fibroblasts in vitro. Biochem Pharmacol 2013;86:1784-90. https://doi. org/10.1016/j.bcp.2013.10.009

23. Ramírez-Fernández MP, Calvo-Guirado JL, de-Val JE, DelgadoRuiz RA, Negri B, Pardo-Zamora G, et al. Melatonin promotes angiogenesis during repair of bone defects: a radiological and histomorphometric study in rabbit tibiae. Clin Oral Investig 2013;17:147-58. https://doi.org/10.1007/s00784-012-0684-6

24. Soybir G, Topuzlu C, Odabaş O, Dolay K, Bilir A, Köksoy F. The effects of melatonin on angiogenesis and wound healing. Surg Today 2003;33:896-901. https://doi.org/10.1007/s00595-003-2621-3

25. Nakamura E, Kozaki K, Tsuda H, Suzuki E, Pimkhaokham A, Yamamoto G, et al. Frequent silencing of a putative tumor suppressor gene melatonin receptor $1 \mathrm{~A}$ (MTNR1A) in oral squamous-cell carcinoma. Cancer Sci 2008;99:1390-400. https://doi.org/10.1111/ j.1349-7006.2008.00838.x

26. Cutando A, Arana C, Gómez-Moreno G, Escames G, López A, Ferrera MJ, et al. Local application of melatonin into alveolar sockets of beagle dogs reduces tooth removal-induced oxidative stress. J Periodontol 2007;78:576-83. https://doi.org/10.1902/ jop.2007.060244

27. Barba-Recreo P, Del Castillo Pardo de Vera JL, García-Arranz M, Yébenes L, Burgueño M. Zoledronic acid - related osteonecrosis of the jaws. Experimental model with dental extractions in rats. J Craniomaxillofac Surg 2014;42:744-50. https://doi.org/10.1016/ j.jcms.2013.11.005

28. Zandi M, Dehghan A, Malekzadeh H, Janbaz P, Ghadermazi K, Amini P. Introducing a protocol to create bisphosphonate-related 
osteonecrosis of the jaw in rat animal model. J Craniomaxillofac Surg 2016;44:271-8. https://doi.org/10.1016/j.jcms.2015.12.010

29. Wayama MT, Yoshimura H, Ohba S, Yoshida H, Matsuda S, Kobayashi J, et al. Diminished progression of periapical lesions with zoledronic acid in ovariectomized rats. J Endod 2015;41:2002-7. https://doi.org/10.1016/j.joen.2015.08.029

30. Jabbour Z, do Nascimento C, El-Hakim M, Henderson JE, de Albuquerque Junior RF. Bacterial profile and bone healing in rats receiving cancer therapeutic doses of bisphosphonates and corticosteroids: a pilot study. Int J Oral Maxillofac Surg 2016;45:1162-9. https://doi.org/10.1016/j.ijom.2015.12.017

31. Cutando A, Aneiros-Fernández J, López-Valverde A, Arias-Santiago S, Aneiros-Cachaza J, Reiter RJ. A new perspective in oral health: potential importance and actions of melatonin receptors MT1, MT2, MT3, and RZR/ROR in the oral cavity. Arch Oral Biol 2011;56:944-50. https://doi.org/10.1016/j.archoralbio.2011.03.004

32. Kara A, Akman S, Ozkanlar S, Tozoglu U, Kalkan Y, Canakci $\mathrm{CF}$, et al. Immune modulatory and antioxidant effects of melatonin in experimental periodontitis in rats. Free Radic Biol Med 2013;55:21-6. https://doi.org/10.1016/j.freeradbiomed.2012.11.002

33. Reiter RJ, Rosales-Corral SA, Liu XY, Acuna-Castroviejo D, Es- cames G, Tan DX. Melatonin in the oral cavity: physiological and pathological implications. J Periodontal Res 2015;50:9-17. https:// doi.org/10.1111/jre.12176

34. Arabacı T, Kermen E, Özkanlar S, Köse O, Kara A, Kızıldağ A, et al. Therapeutic effects of melatonin on alveolar bone resorption after experimental periodontitis in rats: a biochemical and immunohistochemical study. J Periodontol 2015;86:874-81. https://doi. org/10.1902/jop.2015.140599

35. Ruggierro SL. Diagnostic and management of medication-related osteonecrosis of the jaw. In: Fonseca RJ, ed. Oral and maxillofacial surgery. 3rd ed. St. Louis: Elsevier; 2018:507-22.

How to cite this article: Yadegari A, Aminzadeh A, Seyyedkhamesi S, Aminian M. The effect of melatonin on prevention of bisphosphonate-related osteonecrosis of the jaw: an animal study in rats. J Korean Assoc Oral Maxillofac Surg 2020;46:266-274. https://doi.org/10.5125/jkaoms.2020.46.4.266 